\title{
Uma genealogia dos impressos para o ensino da escrita no Brasil no século XIX*
}

\author{
Isabel Cristina Alves da Silva Frade
}

Universidade Federal de Minas Gerais, Faculdade de Educação e Centro de Alfabetização, Leitura e Escrita

\section{Introdução}

No campo educacional, o século XIX é marcado por iniciativas do Império para organizar a educação na Corte e nas Províncias, e em 1827 é instituída uma lei geral que regula a educação nacional. Pode-se dizer que nesse período, e no que se segue a ele, a escola está se constituindo/inventando. Em 1834, o Império passa para as Províncias a administração legal e pedagógica das escolas, o que também nos incentiva a investigar a especificidade das políticas, das ações que instituem a escola, dos materiais e das práticas desenvolvidas em cada local.

* Este estudo é parte de um trabalho de pós-doutoramento realizado na Faculdade de Educação da Universidade de São Paulo (USP) e no Institut Nacional de Recherche Pédagogique (INRP), da França, e contou com financiamento do CNPq e da CAPES. Uma versão deste texto foi apresentada no VIII Congreso Iberoamericano de Historia de la Educación Latinoamericana. Contactos, cruces y luchas en la historia de la educación latinoamericana, realizado em Buenos Aires, de 30 de outubro a 2 de novembro de 2007.
Especialmente em relação à cultura escrita, os estudos de Lajolo e Zilberman (1996) e de Hallewell (1985) relacionados à história do livro e da leitura e várias pesquisas sobre história da educação e da alfabetização naquele período, realizadas por Mortatti (2000), Frade e Maciel (2006) e Maciel (2003), denunciam a precariedade dos materiais impressos que circulam nas escolas e fazem referências ao uso de textos manuscritos de circulação doméstica ou de livros de origem portuguesa para o ensino da escrita.

Com os ventos da República, já no final do período imperial, prenuncia-se uma produção brasileira de livros para ensinar a ler, ressaltando-se a produção de Abílio César Borges. Na República, destacam-se na produção nacional os livros de Hilário Ribeiro e Felisberto de Carvalho. O estudo dos dados editoriais e das instruções dirigidas a professores em pelo menos dois livros, o de Abílio e o de Felisberto, revela que o primeiro foi produzido e impresso na França. Por questões editoriais, o mesmo ocorre com o livro de Felisberto, no qual há referências aos modelos franceses. Também impresso na França, o livro de Hilário faz uma menção ao recebimento de prêmio em exposição 
universal, realizada naquele país. Esses livros também circularam na Província de Minas Gerais, mostrando que, para além de uma organização provincial da Escola de Primeiras Letras, há impressos produzidos em outros locais que são difundidos e utilizados em outras regiões. Esses dados também revelam que há circulação de modelos pedagógicos e de materiais entre países, reforçando a importância de uma análise comparativa.

Em uma análise da produção sobre história da alfabetização, verifica-se que são mais frequentes as pesquisas sobre a circulação e propostas pedagógicas de títulos que circularam nacionalmente a partir da produção de Abílio, e sobre a produção de métodos/ livros para ensinar a ler que responderam às inovações pretendidas com a construção de grupos escolares e a implantação de séries graduadas.

Sobre os materiais que os antecederam, os silabários e as cartas de $A B C$, são encontradas várias citações, em memórias e relatórios de inspetores, que atestam seu uso, e há estudos que partem das críticas aos métodos a eles subjacentes (Mortatti, 2000). No entanto, é necessário trabalhar com novas perguntas ou outras categorias analíticas que permitam ir além das críticas pedagógicas, utilizando referências encontradas na história do livro e na história da cultura escrita. Quando investigamos a produção, a difusão e a utilização de impressos para alfabetizar ${ }^{1}$ ou para iniciar os alunos na leitura escolar, temos adotado, então, os pressupostos da história da educação e, especialmente, os da história da alfabetização, ao mesmo tempo em que empregamos categorias oriundas da

${ }^{1}$ Embora use o termo alfabetizar para o momento contemporâneo, no século XIX encontram-se, nos títulos de livros, nos programas e nas descrições de desempenho de alunos, diferentes termos para designar o aprendizado inicial da escrita. Muitas vezes ele se confunde com o próprio nível de ensino: primeiras letras; outras vezes seu significado aparece no debate público ou nos censos como domínio da leitura (Ferraro, 2009), e nos títulos e nas instruções dos próprios livros como método de leitura. Em outras situações, aparece o termo rudimentos da escrita. história do livro, sobretudo as que se referem ao papel da materialidade.

O objetivo deste artigo é caracterizar e compreender diferentes modelos e formatos de livros escolares para ensinar a ler ou para ensinar os rudimentos da leitura, a partir do início do século XIX. Visando compreender a construção de modelos escolares de livros para alfabetizar, indaga-se: o que são materiais próprios para uma transmissão escolar da escrita? Como se caracterizam? No início do século XIX, que tipo de material circula para o ensino das primeiras letras? Os materiais de uso doméstico e individual seriam aqueles transportados para a escola? Que transformações ocorreram em seu formato?

\section{Origem do estudo, fontes e período investigado}

Baseado nos pressupostos da história do livro e da sociologia de textos apresentados nos estudos de Roger Chartier (1990, 1994, 1996, 1998a e b) e Donald Mckenzie (1991) e nos estudos sobre a história dos livros didáticos de Anne-Marie Chartier (2004, 2007), Alain Choppin (2002), Jean Hébrard (2002) e Agustín Escolano Benito (1997), este trabalho teve origem em uma pesquisa que buscou descrever e analisar a configuração das páginas (mise-en-page) de livros brasileiros que mais circularam no final do século XIX e início do século XX, indicando especificidades de seus formatos e as possíveis relações entre os aspectos gráfico-editoriais e as dimensões pedagógicas do ensino da leitura e da escrita.

No contexto de uma pesquisa mais ampla que gerou a investigação apresentada neste artigo, inicialmente foi selecionado um período que marcou mais acentuadamente a produção nacional de livros para o ensino inicial da leitura e da escrita, que se estendeu de 1867, época da produção de Abílio César Borges, até o início do século XX. Como vários desses livros foram produzidos ou impressos na França, também foi feita uma comparação com um corpus de livros franceses localizados no Institut National de Recherche Pédagogique (INRP) e na Biblioteca Nacional de França, que circularam no século XIX. No entanto, ao investigar os 
títulos mais representativos e a paginação dos livros, ficavam as indagações: os livros inauguram modelos? Herdam modelos? Afinal, o que se usava antes para ensinar a ler? O que se usava antes pode explicar os formatos que encontramos depois? Há modelos que circulam em mais de um país?

Conforme dito anteriormente, no Brasil, antes de uma produção escolar mais autoral, encontramos menções de uso e severas críticas aos abecedários, às cartas de $\mathrm{ABC}$ e aos silabários. Infelizmente, por não terem sido conservados, muitos desses materiais não podem ser analisados diretamente, e é necessário buscar indícios sobre como eles se apresentavam materialmente e sobre alguns significados dessa materialidade no manuseio e uso escolares.

No intuito de compreender formatos anteriores de materiais para ensinar a ler, trabalhou-se com dois tipos de fontes e períodos.

Em primeiro lugar, buscamos indícios da presença de materiais para ensinar a ler e escrever nas escolas, assim como de seus formatos e usos, em documentos primários do início do século XIX. Nesse sentido, foram localizados e registrados vários documentos do Arquivo Público Mineiro, tais como relatórios de professores e inspetores, pedidos de materiais e mapas de desempenho de alunos, os quais totalizam 167 registros, produzidos de 1823 a 1930. Para efeito de nosso objeto de pesquisa, foram selecionados aqueles documentos que faziam menção a materiais para ensinar a escrita, que se encontram enumerados na seção de Referências bibliográficas. Usando dados mais qualitativos, deixamos de citar aqueles documentos que repetem a mesma informação.

Em segundo lugar, foram analisados livros brasileiros conservados que circularam no Brasil desde o final do século XIX e traziam em seus títulos os termos silabário, abecedário e cartas de $\mathrm{ABC}$, visando compreender seus formatos, seus conteúdos e suas esferas de circulação, uma vez que nem sempre um livro destina-se apenas ao uso escolar. A pesquisa com essas fontes foi desenvolvida em diferentes acervos, como o Centro de Referência do Professor de Minas Gerais, a biblioteca do LIVRES/USP e a Biblioteca
Nacional do Rio de Janeiro. O acervo do INRP também foi consultado.

$\mathrm{Na}$ investigação, foi realizada uma busca de livros brasileiros que apresentaram no título as palavras cartas de $\mathrm{ABC}$, abecedários, silabários, mesmo quando as datas não correspondiam ao século XIX. Além disso, foram utilizadas fontes secundárias que discutem modelos de livros franceses, apresentados como abécédaire, alphabet, syllabaire, que poderiam ajudar na análise dos formatos.

Fontes secundárias, como as investigações de Faria Filho, Chamon e Rosa (2006) e Inácio et al. (2006) sobre a história da educação brasileira, sobretudo a respeito da história da educação em Minas Gerais, também se constituíram em base teórica valiosa para se compreender aspectos da escolarização e materiais utilizados no período.

Do ponto de vista metodológico, a investigação baseou-se nos estudos da história da leitura e do livro (Roger Chartier, 1990,1994, 1996, 1998a e b), especialmente no que tange aos conceitos de textos e impressos, aos formatos e aos usos do livro. Para uma análise comparativa, foram selecionados alguns livros franceses que ajudaram a compreender a forma e os usos de abecedários e silabários, assim como alguns termos, como tableau, que aparecem como tabelas/ tábuas nos documentos brasileiros. Além disso, uma pesquisa comparativa permitiu verificar algumas influências de modelos de livros de leitura franceses nos títulos brasileiros, ou mesmo especificidades de usos e formatos em nosso país.

Os resultados da pesquisa serão apresentados em duas partes. Na primeira, usando como fonte pedidos de materiais e mapas de desempenho e frequência de alunos, serão analisados materiais como tábuas, tabelas e outros tipos que circularam no início do século XIX. Nela serão problematizados os usos e os manuseios, as práticas escolares e os conteúdos da escrita e algumas formas de escolarização da cultura escrita. Na segunda, a fonte principal será constituída de materiais brasileiros, como abecedários, silabários e cartas de $\mathrm{ABC}$, conservados em formato de livro, que possivelmente foram utilizados no final do século XIX 
e início do século XX. Esses materiais serão descritos do ponto de vista de sua forma e seu uso; também serão consideradas as possíveis práticas escolares e não escolares para as quais eles indiciam.

\section{As tábuas e as tabelas}

O uso de materiais como tábuas e tabelas no século XIX é citado nas pesquisas realizadas na Espanha (Benito, 1997), na França (Anne-Marie Chartier, 2004) e no Brasil (Inácio, 2003; Inácio et al., 2006). Fatores comuns ligados à escolarização e aos modelos de materiais podem explicar essa circulação, mas é preciso verificar, em cada país, se esses materiais ligam-se a outros textos impressos; por quanto tempo circulam; se substituem os livros em determinado momento; se são utilizados de forma coletiva ou contam com a posse individual por alunos; e, finalmente, se sua circulação deve-se a fatores econômicos e/ou pedagógicos.

Como já mencionado, na Província de Minas Gerais também circularam tábuas, tabelas e cartas. Por dados indiciais, pode-se dizer que são tabelas e tábuas que se relacionam mais diretamente ao ensino da leitura, enquanto os traslados impressos são materiais, também citados no período, que serviriam especificamente como modelos para a escrita. Cartas parecem ser materiais avulsos, em páginas separadas. A forma e a função desses materiais será melhor tratada no decorrer desta seção. Embora esses materiais sejam específicos para o ensino da leitura ou da escrita, eles dialogam com um conjunto de materiais que ajudam a produzir a própria escola.

As pesquisas sobre a escolarização na Província de Minas Gerais no século XIX (Inácio et al., 2006; Frade et al., 2006) e investigações recentes evidenciam a utilização de outros suportes que não são livros, mas são impressos. Nesses estudos, aparecem materiais relacionados à instituição do ensino mútuo nas primeiras décadas do século XIX e há indícios de que um dos impressos para ensinar a ler e escrever caracteriza-se como uma grande página ou cartaz, ou talvez uma grande página de um livro para todos.

Ao mesmo tempo, esse material pode ser um tipo de suporte e um tipo de gênero textual que guarda relações com usos propriamente escolares e que tem ligação com um método oficial de ensino, o método mútuo ou lancasteriano, que se pretendeu instalar no Brasil nas primeiras décadas do século XIX (Inácio et al., 2006).

Do ponto de vista do ensino da escrita, alguns desses suportes denominados tábuas ou tabelas precisam estar à altura dos olhos de uma classe, que, organizada em grandes bancos, deve olhar atenta para os comandos de um aluno monitor, que vai mostrando letras, nomeando-as e pedindo sua reprodução em caixas de areia: estamos, então, entre uma leitura permanente e uma escrita efêmera. Na França, esse exercício parece se constituir em uma preparação para usar o livro. Referindo-se à organização do ensino descrita em um alfabeto cristão de 1839, Anne-Marie Chartier (2004, p.14) comenta que "a divisão de iniciantes trabalha sobre grandes quadros/tableau $x^{2}$ de letras que o professor mostra com uma vara, depois um quadro/ tableau de sílabas, alternando exercícios coletivos, de leitura em coro ou individuais antes de abrir o livro" (tradução minha).

Analisando pedidos de professores mineiros no mesmo período, podemos pensar que no Brasil ocorriam procedimentos semelhantes. Entretanto, será que os alunos manuseavam livros, folhetos ou, a cada vez, uma folha solta? Com certeza, os gestos em torno de um quadro ou tabela que apresenta uma dimensão bidimensional não serão os mesmos quando esses materiais estiverem sequenciados em um livro que se pode folhear. ${ }^{3} \mathrm{O}$ uso dessas tabelas também possui uma

${ }^{2}$ A autora usa a palavra tableau, que em francês pode significar tabelas, quadros, telas, painel. Pelas informações sobre como funcionavam os materiais em imagens da época, temos a indicação de que esse material pode ser um quadro para apoiar uma tabela ou um grande cartaz que todos podem enxergar numa parede, por exemplo.

${ }^{3}$ Algumas relações entre esse tipo de gênero textual e os instrumentos do pensamento foram trabalhados por Jean Marc Chatelein, na comunicação denominada Surfaces du savoir: la publication en tableaux au XVIIe siècle, no âmbito do Seminário "Les Outils de la Pensée", organizado em 2007 pela Fondation Maison des Sciences de l'Homme e Musée National d'Ethnologie Osaka. 
dimensão específica: é preciso saber consultar, localizar, talvez decorar toda a sequência, ou mesmo operar com algumas combinações que exigem o ensino/aprendizado de técnicas intelectuais. Os pedidos de tabelas separadas com determinados conteúdos indicam que esse suporte constitui uma folha avulsa que talvez seja um material de leitura intensiva que exige repetido manuseio. Em um inventário de objetos deixados por um professor (Documento 2, apresentado adiante) encontramos a descrição de um material denominado 67 taboletas para tabelas. Podemos dizer que isso indica ter sido necessário apoiar em algum suporte especial esses materiais avulsos. Os suportes para as folhas avulsas podem ter servido também para melhor manuseio e conservação das folhas. Seriam essas folhas soltas a reprodução das mesmas tabelas existentes nas grandes tábuas? Esses materiais seriam impressos?

Conforme vários estudos de Roger Chartier, há livros que são impressos e livros manuscritos, e o que os une na definição de livro é o formato códice - uma coleção de folhas amarradas ou coladas umas às outras, que podem ser manuseadas e folheadas em uma sequência. Mas há também impressos que não são livros. No caso das tabelas ou tábuas, podemos dizer que são, possivelmente, folhas soltas que fogem ao formato códice, mas podem ser impressas ou manuscritas. Consideramos que o termo "impresso" refere-se a uma técnica de reprodução a partir da tipografia, que pode ser tanto artesanal e produzida quanto encomendada em uma tipografia, ou ser um material padronizado e comercial feito por alguma tipografia/livraria. Essa é uma questão relevante porque podemos pensar na possibilidade de um professor copiar e mandar reproduzir poucos exemplares para uma classe, ou numa produção editorial que visa a um mercado escolar. Se esse material é vinculado a um método que apresentava materiais específicos e padronizados, como aqueles que são reiteradamente pedidos pelos professores como condição para a implantação do ensino mútuo que se pretendeu iniciar nas escolas brasileiras, podemos pensar em um material produzido em maior escala. Ao contrário, se funciona como material de apoio a professores que usam métodos mistos, que mesclam várias alternativas, inclusive a de atender aos alunos individualmente, podemos levantar a hipótese da existência de materiais impressos singulares, mas possíveis de ser produzidos apenas em cidades que contavam com tipografias.

Inventários e pedidos de professores demonstram que havia material padronizado, e possivelmente impresso, a ser utilizado para auxiliar o desenvolvimento das atividades, daí constatarmos o espanto de um professor ao ter de copiá-los de forma manuscrita.

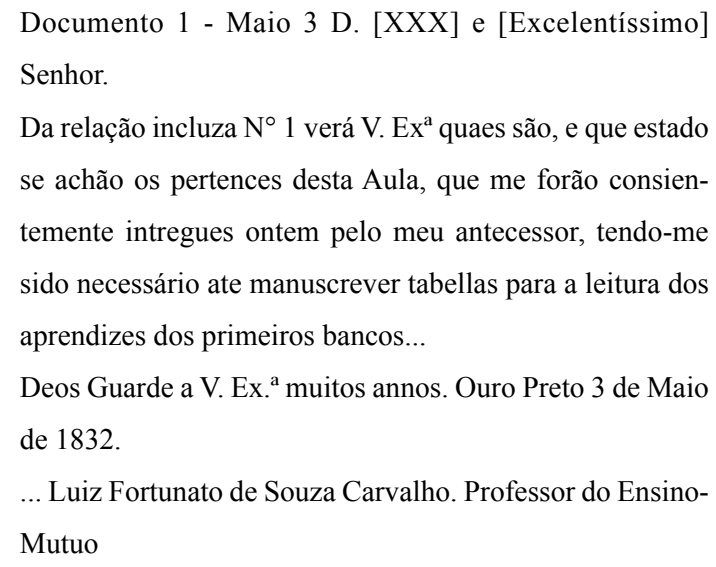

Deos Guarde a V. Ex. ${ }^{\text {a }}$ muitos annos. Ouro Preto 3 de Maio de 1832.

... Luiz Fortunato de Souza Carvalho. Professor do EnsinoMutuo

(Arquivo Público Mineiro, identificação: PP 1/42, caixa 01, envelope: 47 , folha 1 )

A lista de utensílios entregues a um professor permite compreender os conteúdos que acabam identificando as próprias tabelas:

Documento 2 - Relação dos utencilios do Ensino-mutuo,

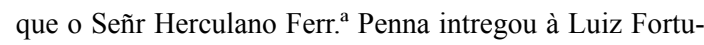
nato de $\mathrm{Sz}{ }^{\mathrm{a}}$

... 32 Tabellas contendo artigos da Constituição

3 [D. $\left.{ }^{\mathrm{a}} \mathrm{s}\right]$ das formas do alphabeto

1 [D. $\left.{ }^{\mathrm{a}} \mathrm{s}\right]$ das letras consoantes

2 [D. $\left.{ }^{\mathrm{a}} \mathrm{s}\right]$ das articulações triplas

$1\left[\mathrm{D} .{ }^{\mathrm{a}} \mathrm{s}\right]$ das caracteres numericas

1 [D. $\left.{ }^{\mathrm{a}} \mathrm{s}\right]$ da divisão de quantidades

67 Taboletas para tabelas

... Pequenas colleções de Cartas

18 Traslados impresos...

Ouro Preto 3 de Maio de 1832.

Luiz Fortunato de Souza Carv.

(Arquivo Público Mineiro, identificação: PP 1/42, caixa 01, envelope: 47 , folha 2 ) 
Conforme o documento a seguir, a identificação dos materiais que fazem parte de um pedido de professor que passa a ocupar a mesma cadeira de ensino indicia que cada tabela possui uma especificidade e que essas podem ter sido utilizadas separadamente. Além disso, elas são apresentadas numa progressão detalhada que vai do alfabeto às "articulações maiores com divisão de sylabas", que podem ser pequenas frases ou textos.

Documento 3- Rellação dos utencilios, que exige com mais urgência a Aula do Ensino Mutuo desta Imperial Cidade 30 Exemplares da Grammatica Brasileira por Borges Carneiro (vendem-se na Typografia de Silva) 30 Ditos de Arithmética conforme as regras de Bezout (na mesma typografia)

30 Ditos da Doutrina Christã (dito)

10 Ditos das regras de Orthografia (dito)

40 Traslados impressos, e diferentes

Tabellas das formas do alfhabeto

$\mathrm{D}^{\mathrm{a}}$ dos caracteres numericos

Ditas de sylabas de duas letras

Ditas de ditas de três

Ditas de ditas de quatro

Ditas de ditas de cinco

Ditas que contenhão articulações maiores com divisão de sylabas $[\ldots]$

Ouro Preto 3 de Maio de 1832.

Luiz Fortunato de Sz ${ }^{\mathrm{a}}$ Carv.

(Arquivo Público Mineiro, identificação: PP 1/42, caixa 01, envelope: 47 , folha 3 )

Como uma classe de ensino mútuo comportava um número grande de alunos, de vários níveis diferenciados, é necessário desenvolver mais pesquisas para relacionar melhor o uso de um determinado material impresso ao conteúdo que cada classe subdividida em bancos deveria estudar, pelo menos para atender aos princípios de organização, bastante divulgados n'O Universal $^{4}$ (Faria Filho et al., 2006). Naquele momento, vários textos normativos divulgavam o método

${ }^{4}$ Jornal publicado em Ouro Preto, Província de Minas Gerais, de 1825 a 1842 . mútuo: os relatórios de inspetores criticavam a sua não utilização, e os professores pediam materiais específicos para dar conta de sua implantação. No entanto, isso está no plano do discurso, e, se os professores utilizavam, na prática, métodos de organização do ensino não oficiais e materiais próprios, urge desenvolver pesquisas com outras fontes para compreender práticas que fogem à normatização.

Em vários pedidos são solicitados livros que consideramos ser de uso profissional do professor, compêndios relacionados a algumas áreas específicas, como matemática e história, que talvez ainda fossem utilizados para servir de consulta aos professores, e materiais de leitura próprios de uma fase de leitura corrente. O programa instituído pelo Império deixa ver que alguns livros faziam parte de outros conteúdos, embora estivessem relacionados à leitura. A Lei Geral do Ensino de 1827 prescreve como programa:

\footnotetext{
Os professores ensinarão a ler, escrever, as quatro operações

de arithmética, prática de quebrados, decimaes e proporções, as noções mais geraes de geometria pratica, a grammática de língua nacional, e os princípios da moral christã e da doutrina da religião catholica e apostólica romana, proporcionados à comprehensão dos meninos; preferindo para as leituras a Constituição do Império e a História do Brazil. (apud Inácio et al., 2006, p. 59)
}

É muito difícil construir uma história do campo do saber alfabetização quando a estudamos em um período no qual a própria escola precisa preocupar-se com outras materialidades, como a organização dos espaços, de tempos e de materiais, em um período em que estão todos na mesma classe, com experiências escolares e não escolares diversificadas. No entanto, alguns mapas indicam que a medida dada pela sequência das tabelas, consideradas como suportes de escrita, parece constituir-se num vocabulário comum que favorece a troca de informações sobre o desempenho dos alunos em torno da cultura escrita. O uso do termo "lê Ba", por exemplo, pode designar tanto a leitura da primeira sílaba da linha de uma tabela como todo o conteúdo da tabela de sílabas diretas, conforme documento a seguir: 
Documento 4 - Relação dos Alunnos que assistem na Escola de Manoel da Alcensão Ferreira a pouco principiarão nesta Villa do Paracatu do Príncipe são os seguintes.

... NOME Pardo vindo de Outras Escholas lendo escriptos soletrando, escreve Garrafal.

NOME Branco com hus mezes de escholas, e lê Ba.

NOME pardo com dous mezes de Eschola está lendo o Ba.

Paracatû do Príncipe 22 de novembro de 1823.

Manoel da Alcenção Ferreira

(Arquivo Público Mineiro, identificação: PP 1/42, caixa 01, envelope: 07, documento: 09, folha 01)

Outras vezes, os mesmos tipos de divisões e terminologias existentes nos termos das cartas que foram solicitadas como suportes/materiais constituem-se no modo de descrição do desempenho dos alunos e aparece também um termo mais genérico, "cartilha", talvez um verdadeiro livro a ser lido:

Documento 5 - Rellação dos Discípulos, que [XXX] Domingos da Costa Braga

NOME branco, lê escripto de mão, e Cartilha, faz conta a sommar e diminuir, está com 1 anno, e 4 mezes de Escolla, escreve Letra fina.

NOME branco, lê escripto de mão, e Cartilha, faz conta de sommar, e diminuir, escreve Letra fina, está com 1 anno, e 1 mez de Escolla.

NOME branco, Lê escripto de mão, e escreve A.B.C está com 8 mezes de Escolla.

... NOME pardo, lê escripto de mão, e varias [Autory] de Letra redonda, escreve Letra fina, faz conta de juros, está com dez mezes de Escolla.

NOME pardo, está Lendo Carta de Nomes, e escreve A.B.C está com 4 mezes de Escolla.

NOME pardo, Lê escripto de mão, e escreve Letra grande, está com 8 mezes de Escolla.

NOME mestiço, está Lendo Carta de Nomes, e escreve Letra grande, está com 4 mezes de Escolla.

Paracatû do Príncipe 24 de [XXX] de 1823.

Domingos da Costa Braga

(Arquivo Público Mineiro, identificação: PP 1/42, caixa 01, envelope: 07 , documento: 9 , folha 02 )
No entanto, outras descrições desses mapas nos intrigam: a julgar pelas habilidades descritas. Parece que há alunos que "leem letra de mão e escrevem ABC" e com poucos meses de escola. Alguns deles teriam vindo para a escola para aprender, de forma sistematizada, determinadas técnicas possíveis de ser aprendidas num processo de escolarização, como a escrita, por exemplo? Nesse sentido, pesquisas sobre uma educação doméstica - e, quem sabe, abrangendo meios populares - podem nos indicar até que ponto é a escola que ensina a ler, em determinados casos.

Nos mapas também aparecem dados indicando, por exemplo, que os alunos ainda não leem bem, mas conhecem os princípios da Doutrina Christã..$^{5}$ Sendo assim, não parece que este último material tenha sido usado para ensinar a ler ou para uma leitura por soletração, e seu conteúdo pode ter sido transmitido de forma oral pelo professor. Outras descrições permitem verificar que os conhecimentos escolares dos conteúdos da doutrina vão ter uma função extraescolar, no exercício religioso da missa ou, quem sabe, para a missa na própria escola? Outras vezes encontramos uma descrição que reúne habilidades de leitura e domínio da doutrina. Além disso, os termos Senhora Carta e Carta de Padre Nosso, encontrados nos fragmentos de um mapa reproduzido a seguir, podem manter alguma relação com o uso de textos religiosos no início da escolarização e com tipos de impressos em folhas avulsas:

Documento 6 - Rellação dos meninos, q actualmente freguentão a Escolla das primeiras Letras nesta $\mathrm{V}^{\mathrm{a}}$ do $\mathrm{Pa}$ racatu... O seguinte

NOME 1 anno e 3 mezes escrevendo Letra fina contando conta de multiplicar por 3 Letras, bem desembarraçado no Ler letra de mão arredondada, e na aplicação $[X X X]$ ajudar da Missão, e [XXX] he pardo.

${ }^{5} \mathrm{Na}$ descrição de desempenho de alguns alunos, encontramos a expressão "Está escrevendo bastardinho, e não desenvolve-o, lê malissimamente: está na $2^{\circ}$ operação. No que leva vantagem é na Doutrina. Não tem talento, porém é estudioso" (Documentos do Arquivo Público Mineiro, IP3/2, caixa 2, envelope 56, Mappa Trimestral da Freqüência dos Alunnos da Aula. 1868). 
NOME branco 1 anno, e 2 mezes principiando a escrever letra fina, e contando Conta de multiplicação por 3 Letras, e já Lê letras de mão arredondada, e bem adiantado na explicação dareza no ajudar a Missa.

NOME (José) e seu Irmão NOME (Francisco) entrarão a

21 de Janr. De 1823, [etiverão] doentes [XXX] e quatro mezes, e está José adiantado mais q Francisco, e já escreve A.B.C pequeno, e grande, e Francisco em carta de Bal por ser gago.

NOME pardo entrou a 7 de Abril de 1823 e está Lendo Carta de Padre Nosso.

NOME 8 mezes, e está lendo escripto e letra redonda, fazendo conta de Sommar, e escrevendo Letra grande, he pardo.

NOME p. e está em carta de nome.

NOME p. [XXX] e está lendo escrito, e [Senhora Carta] e letra redonda e escrevendo Letra merão fazendo conta diminuir.

NOME, negro 1 anno e dous mezes está lendo escrito, e taboada, e escreve A.B.C pequeno.

NOME negra está 1 anno e quatro mezes lendo [Senhora Carta] e escrito, Letra redonda e escrevendo Letra meiam. Villa do Paracatu do Príncipe 21 de Novembro de 1823.

Manoel Pereira de Castro [XXX]

Arquivo Público Mineiro, identificação: PP 1/42, caixa 01, envelope: 07, documento: 09, folha: 03)

Dentre alguns materiais específicos, os traslados impressos - modelos de escrita para os alunos copiarem - vão completar uma possível lista de materiais usados no início da alfabetização, mas não sabemos se eram trabalhados com iniciantes, uma vez que o ensino simultâneo dos princípios da leitura e da escrita começa a aparecer como discurso pedagógico e em manuais e livros produzidos no final do século XIX, principalmente nos de Felisberto de Carvalho. ${ }^{6}$

${ }^{6}$ Felisberto foi um autor com expressiva produção de livros didáticos. Escreveu uma coleção especial com cinco volumes, destinada à leitura, e produziu, em 1892, O Primeiro Livro de Leitura, material que circulou em várias regiões do país. Segundo estudos de Cabrini (1994, p.29), “como professor, Felisberto atuou na escola primária anexa à Escola Normal de Niterói, na própria Escola Normal, em escolas particulares e no Instituto de Educação do Distrito Federal, ocupando cadeiras de Português e Educação
Não podemos, no entanto, confundir um discurso pedagógico com determinado uso prático da escrita e da leitura que ocorrem juntos nas escolas do começo do século XIX: os dados mostram simultaneidade. Seria interessante, também, iniciar estudos em outras províncias para evidenciar práticas de leitura e de escrita nas escolas.

Pelas informações existentes nos documentos apresentados anteriormente, parece que os alunos que leem letra escrita ${ }^{7}$ são os que passam a escrever, mas ficam algumas indagações: a leitura oral pode ocupar algum tempo do aprendizado, mas em uma turma com muitos alunos, em diferentes níveis, é preciso distribuir outras atividades para facilitar a gestão de um tempo do trabalho no qual é necessário que alguns alunos realizem tarefas, individualmente, para que se possa dar atenção a outros. Sendo assim, durante as tarefas individuais, o que fariam os alunos que ainda não sabiam ler a não ser gastar o tempo com uma tarefa disciplinada de escrita? Em contrapartida, para aqueles que não sabem ler, mas dominam os princípios da doutrina, podemos supor uma transmissão pela oralidade. Atividades de escrita, de leitura e de transmissão oral precisam ser bem administradas, e cada uma delas exige um tipo de material escolar: cartas e tabelas soltas, lousa, areia e folhas soltas, livros para o mestre, modelos de escrita manuscrita para ler e para escrever.

No trabalho de Inácio et al. (2006) é apresentada a argumentação sobre o uso do tempo, feita em 1826 por um divulgador do método do ensino mútuo, o professor mineiro José Carlos Mayrink, que dá pistas sobre o uso da escrita em classes com diversos agrupamentos. Ao descrever o que seria um dia de aula naquele período, Mayrink supôs que um professor deveria primeiro colocar os alunos para escrever, atividade que levaria pelo menos uma hora, uma vez que o professor deveria criar condições materiais para que

Moral e Cívica. [...] Seus livros são resultado dessas experiências pedagógicas realizadas nas diversas cadeiras que ocupou como professor".

${ }^{7}$ Podemos pensar que este termo se refere a ler letra manuscrita. 
essa escrita ocorresse: debuxar ${ }^{8}$ materiais, riscá-los etc. Concluída essa escrituração, estimou que o professor fizesse os alunos contar ou ler, e restariam somente duas horas para esse trabalho. Mayrink calcula que, numa escola com 60 alunos, nas duas horas restantes haveria apenas dois minutos para explicar, a cada aluno, contas e leitura.

Sendo assim, é preciso distinguir algumas diferenças entre as atividades vinculadas às práticas de escrita: a primeira que é relacionada aos aspectos materiais da utilização de objetos da cultura escrita; a segunda que se refere à organização das atividades em relação ao uso dos tempos escolares; a terceira que depende de materiais disponíveis; e, além delas, uma quarta que se liga especialmente à discussão dos métodos que são denominados hoje como de alfabetização e que têm o ensino da cultura escrita (leitura e/ou escrita) como conteúdo central. Por fim, é preciso separar as normatizações do período das práticas possíveis de ser realizadas com os materiais de leitura e de escrita de que se dispunha.

Indagando, mais uma vez, sobre o significado específico de materiais solicitados pelos professores e sobre sua relação com outra utilização social, podese estabelecer uma hipótese de que quadros, tabelas e "cartas" são típicos do espaço escolar, ou seja, são produzidos para a escola visando ao ensino da leitura e da escrita. Em que outro espaço haveria uma função para exposição e circulação dessas "grandes páginas" impressas e mesmo dessas folhas avulsas e com esses conteúdos? Além disso, há nelas um tipo de formalização que parece ligar-se não às práticas sociais de uso de impressos, mas a uma técnica intelectual para aprender/ensinar o sistema alfabético de escrita.

Talvez eles sejam os materiais que vão preparar os alunos para manusear os futuros livros, uma vez que, naquele período, os livros eram escassos. Outra explicação para seu uso, concomitante ao momento em que são citados os livros, pode ser atribuída a razões econômicas (um folheto para cada aluno possivelmente implica menos gasto com papel e impressão do que

${ }^{8}$ Debuxar significa produzir esboços. um livro inteiro) e por razões pedagógicas relacionadas ao fácil manuseio e ao fato de professores e aprendizes poderem concentrar a atenção em apenas um aspecto da progressão do conteúdo. Muitas vezes, a presença/ permanência de determinado material escolar ocorre por seu valor pragmático e pedagógico, e muitos fatos não se explicam pela ausência ou pela precariedade de recursos para a aquisição de outros materiais.

Buscando ampliar a discussão, outras perguntas são relevantes: os materiais que aparecem soltos/destacados seriam partes selecionadas de livros que circulavam em outros meios? Ao contrário, têm existência própria e são, depois, reunidos para formar um suporte livro? Onde e em que lugar eram produzidos?

Uma breve análise de um corpus de 25 livros franceses para alfabetização, conservados na Biblioteca do INRP/França, publicados entre as décadas de 1850 e 1890 do século XIX, vai mostrar que algumas tabelas de dupla entrada - com dados numa coluna vertical e outros na coluna horizontal, cuja leitura depende dos cruzamentos entre as duas entradas - podem ser "transferidas" para dentro dos livros com a denominação tableau. No entanto, embora pareçam com as tabelas de sílabas, algumas delas podem ser utilizadas de modo mais complexo - e mesmo vendidas à parte para o ensino da leitura. Nesse corpus, encontramos uma tabela que é o próprio método, sendo necessária uma metodologia para utilizá-la (Notice pédagogique..., 1889). Outra forma é um folheto, anexo ao livro de Dessirier (1853), que podia ser comprado separadamente do livro. Trata-se de uma tabela de dupla entrada, que, segundo o autor, segue um modelo pitagórico utilizado antes para o ensino da multiplicação. As tabelas, embora pareçam simples na cultura gráfica que herdamos, exigem um tipo específico de conhecimento para seu uso; os livros didáticos franceses do final do século XIX ainda vão apresentar maior diversidade e sofisticação dos dispositivos visuais. Isso se concretiza na apresentação de diagramas, de ilustrações e de tabelas que tornam mais complexas as operações de uso da página escrita.

Retomando as pistas dos pedidos em Minas Gerais, constatamos a solicitação de Doutrina Christã, 
gramáticas e tratados de ortografia. Mas, no tocante aos materiais utilizados para iniciantes, parece que são as tabelas, as cartas e os traslados impressos os materiais com os quais os aprendizes trabalham. Para se chegar à utilização de materiais que são livros, talvez denominados com o mesmo nome, como Cartas do ABC e/ou de Silabários, pode-se imaginar que foi necessário um certo percurso: tanto das práticas e dos gestos como da materialidade da produção de impresso, sob a forma de livro em menor formato, para ser utilizado individualmente pelos alunos. $\mathrm{Ou}$, quem sabe, apenas como material de consulta para os professores. Mas ainda restam outras perguntas: seriam as cartas do $\mathrm{ABC}$ folhetos? Seriam os silabários livros? Pouco sabemos sobre o formato desses materiais, e os estudos realizados em outros contextos podem nos ajudar a estabelecer hipóteses sobre suas características.

\section{Abecedários, cartas de $A B C$, silabários: diferentes significados}

No tópico anterior, trabalhamos a descrição de materiais impressos que não se constituem como livros, uma vez que não são apresentados no formato códice. Conforme já foi salientado, há diversas pesquisas que atestam o uso de materiais manuscritos no ensino das primeiras letras (Inácio et al., 2006) e, mais no final do século XIX, há discursos pedagógicos de autores e outros intelectuais criticando e condenando o uso das cartas de $A B C$ e de silabários (Mortatti, 2000). Nesse item, são apresentadas pesquisas que possibilitam compreender os diferentes significados desses termos, as características físicas e de conteúdo dos abecedários e suas formas de uso. Talvez esses estudos permitam compreender melhor as características dos materiais brasileiros denominados cartas de $\mathrm{ABC}$ e silabários, os quais serão discutidos na parte final deste texto.

Estudando os livros da Bibliotèque Bleue, produzidos pelos impressores de Troyes, no século XVII, Jean Hébrard (2002, p. 11) afirma que, entre livros destinados a outras funções, aparecem livros didáticos destinados aos escolares ou "àqueles que querem aprender sem mestre". Entre os livros de uso escolar, o autor seleciona um tipo específico de livro, o abecedário, ressaltando:

\begin{abstract}
Entre os livros de uso escolar, o abecedário é aquele que, certamente, representa a maior promessa de venda. Sob o nome de Instruções Cristãs - é assim que são chamados na França do leste - ele é, por excelência, o livro escolar do iniciante e, frequentemente, o único livro que ele possui. É verdade que ele oferece em um mesmo conjunto os instrumentos da primeira alfabetização e os textos essenciais da liturgia católica. (p. 12)
\end{abstract}

O autor também observa que os impressores de Troyes não têm o monopólio de sua produção, pois o abecedário "é um dos produtos de base de todos os pequenos impressores, particularmente o da província". Analisando os abecedários produzidos em Troyes, o autor observa que seu formato pode ser de uma folha, uma folha e meia ou três folhas e que há menção, em diversos catálogos, de alfabetos por sílabas. Segundo o autor:

\section{[...] o abecedário situa os impressores do lado de uma tradição editorial que se apoia nas obras sem autoria, repos- tas ano após ano, sem a preocupação de inovar, em um domínio no qual a permanência e a perenidade continuam os maiores critérios de uma qualidade que se obtém sem despesas. (p. 15)}

Comentando sobre outras obras escolares publicadas no período, Hébrard faz um alerta: "é delicado consignar cada um destes títulos à ordem escolar. As mesmas obras têm, com efeito, múltiplos usos, e a transmissão dos saberes elementares não implica obrigatoriamente na sua escolarização" (p. 15-16). Segundo Hébrard, o objetivo da escolarização no Antigo Regime era preparar para a comunhão e transmitir saberes elementares. Após a Revolução, uma inspeção realizada por Guizot, em 1833, constatou que a maior parte dos livros usados pelas escolas rurais vinha do século anterior. Nas escolas de crianças mais pobres, o abecedário ou um silabário e o catecismo. Para as 
escolas de crianças menos pobres, acrescenta-se, de forma irregular, uma gramática francesa, uma aritmética e a história da França.

Além disso, existem abecedários não populares que circularam na França. $\mathrm{O}$ uso de abecedários ilustrados pelas famílias durante todo o século XIX é comentado por Anne-Marie Chartier (2004, 2007). Ela nos revela que esse pode ser um material luxuoso e não tem uma destinação para o público escolar. É para ser consultado em espaços privados e domésticos e não importa que as crianças sejam muito novas. A ideia de certa precocidade no domínio da leitura incentiva o uso de alfabetos ilustrados no âmbito da transmissão familiar da escrita.

Os abecedários ilustrados são livros de imagens que pretendem provocar nas crianças pequenas o gosto por aprender a ler. Apesar de aparecerem numa sequência de $\mathrm{A}$ a $\mathrm{Z}$, esses abecedários podem ser consultados em qualquer ordem, de forma não linear, como um livro de imagem, e a criança pode deter-se numa letra ou em uma ilustração com a ajuda de um adulto e demandar o que está escrito. Quando a criança passa a interessar-se pelo livro, sugere outra pedagogia utilizada pelos familiares. Aconselha-se que se ensine o nome das letras, que elas sejam reconhecidas fora da ordem, que seja memorizado um pequeno estoque de sílabas e de palavras a ser pronunciadas diretamente e depois soletradas. Quando a criança consulta o alfabeto ilustrado, poderá reconhecer e recordarse de algumas sílabas conhecidas. É um ensino sem sequência, livre, baseado em interações familiares e sem reflexão sistemática.

Esse é um ótimo exemplo que nos revela que as pedagogias referidas à transmissão familiar são voltadas para certo conteúdo, têm intencionalidade apesar de não se ter um procedimento sistemático de análise -, mas ocorrem em condições especiais, no âmbito de uma transmissão que é individual.

Analisando as características materiais e os aspectos de sua utilização, constatamos que esse tipo de abecedário é dirigido às elites, e sua posse individual possibilita uma série de apropriações no espaço privado. Seu uso depende também de comportamentos cul- tivados das famílias e de determinadas competências e disposições para interagir com os filhos em torno da escrita. Essa pedagogia "natural", muito próxima das relações e dos usos da escrita no espaço doméstico, é bastante diferente de um processo institucionalizado que vai ocorrer depois pela transmissão escolar, seja ela feita por professores que abrem pequenas escolas, seja em escolas privadas e depois públicas.

Segundo Faria Filho et al. (2006), na escolarização vai tornar-se central a discussão dos métodos de ensino: o individual, que ocorre durante o atendimento que se dá numa classe a cada aluno em separado; o método mútuo, que trabalha com classes enormes, em que cada banco é uma classe, um nível, contando com monitores para ajudar o professor; e, finalmente, o método simultâneo, que, trabalhando em classes menores e supostamente homogêneas, vai criar estratégias de ensinar a todos, no mesmo tempo e lugar, o mesmo conteúdo. Esse tema vai ser objeto de discussões durante a constituição de sistemas educacionais, na França e no Brasil, por exemplo, quando a educação sai do âmbito familiar e vai para o âmbito coletivo da escola.

Retomando as duas formas de circulação dos abecedários na França, a dos impressos luxuosos existentes em uma biblioteca particular e a dos materiais populares que vão circular para a catequese do povo e, depois, nas escolas, constatamos ser o alfabeto o livro que introduz os iniciantes na cultura escrita. Sabemos que ele também é dotado de uma permanência decorrente de questões editoriais e de seu valor de uso e que as escolas públicas vão utilizar materiais parecidos.

Haveria, no Brasil, algum material conservado que nos mostra alguma semelhança com aqueles descritos nas pesquisas francesas? Uma breve consulta à pesquisa de Ségolène Le Men (1984) sobre 700 abecedários franceses ilustrados do século XIX, conservados na BN/França, vai mostrar uma profusão de títulos a ser consumidos na educação familiar. Talvez esses não sejam os materiais que circularam no Brasil, uma vez que parece ser principalmente a escola que apresenta a cultura escrita à criança. Como não encontramos citações desse material nos inventários e nos pedidos 
de escolas, pode ser que materiais mais populares tenham servido de apoio ao ensino escolar.

As informações sobre o formato de alfabetos populares de Troyes, dadas por Jean Hebrárd, talvez nos aproximem de um modelo que pode ter circulado nos meios escolares brasileiros: "eles não são, portanto, propriamente falando, os livros de cordel. Mas conservam todas as suas características" (2002). O autor observa que eles são compostos em formas irregulares e mal justificados, impressos com tipos muito usados que pertencem a fundições heterogêneas e com xilogravuras típicas da Bibliothéque Bleue, com cenas de santos. Explicitando o conteúdo de alguns deles, comenta aspectos de sua homogeneidade, caracterizando a primeira parte dos livros do seguinte modo: "muito sucinta com diferentes quadros de letras, sinais de pontuação, abreviações de ligaduras (em romano e em itálico, em capitais e em caixa baixa, o todo em dimensão decrescente), quase sempre acompanhadas de dez algarismos árabes [...], segue-se então um quadro de sílabas" (Hebrárd, idem, ibidem). A segunda parte é composta de preces essenciais.

Descrevendo os abecedários ilustrados do século XIX, Anne-Marie Chartier (2004, 2007) recupera sua origem nos alfabetos populares publicados em Troyes e Rouen como livros de bolso. Sobre um folheto dobrado em quatro ou em oito, é impresso o alfabeto, uma breve lista de sílabas que ocupa uma ou duas páginas, e depois uma prece em latim. Quando o livro possui maior número de páginas, é o número de preces que aumenta. Parece ser esse o formato padrão, e os dois pesquisadores constatam que, quando esses abecedários possuem número maior de páginas, poucas páginas são destinadas às instruções didáticas, ou seja, não há muitas páginas para apresentar diferentes modelos de alfabetos, várias tabelas com silabários, sinais de pontuação e exercícios de soletração prévia que ajudem na transmissão dos princípios da leitura. Essa parte é reduzida às páginas iniciais.

$\mathrm{Na}$ França, os abecedários parecem circular antes da instituição de um processo de educação escolar popular e ora separam, ora juntam os objetivos ensinar a ler e ler para aprender a catequese. Ou seja, muitos livros de preces são usados para ser objeto de soletração e ensinar a ler com a seguinte especificidade: os textos a ser lidos são aqueles já conhecidos e decorados pelo cristão.

Voltemos ao Brasil, analisando outras denominações que encontramos nos relatórios ou prefácios de livros: as cartas de $A B C$. Teriam elas esse modelo ou são simplesmente uma forma de reprodução das tábuas usadas na sala de aula ou, quem sabe, a sua inspiração? Essas vinham em forma de folheto/pequeno livro ou de um livro mais encorpado? As cartas de $A B C$ seriam o mesmo que silabários? Seriam seguidas de textos religiosos ou laicos? Em diversos estudos, como o de Mortatti (2000), encontramos as expressões: cartas de ABC, cartas de silabas e cartas de nomes. Seriam esses folhetos separados ou eles seriam distinguidos, nos relatos de alunos e nos relatórios de professores ou prefácios de livros, apenas pelo processo metodológico que impôs seu uso? A análise de alguns indícios, ao final deste texto, poderá problematizar algumas dessas questões.

Esses silabários/abecedários conservados não contêm os textos da liturgia católica. Comparando as descrições dos abecedários cristãos e de seu uso na França, podemos dizer que, apesar de existirem no Brasil normas sobre o ensino e a leitura da Doutrina Christã nas escolas e de haver relação estreita dos interesses da Igreja e do Estado no período imperial, parece faltar ao contexto brasileiro o que constituiu, na França, um projeto de educação popular em escolas católicas, que reúne, no mesmo material, princípios da leitura e textos da liturgia. Sendo assim, um abecedário ou uma carta de $\mathrm{ABC}$ pode apresentar apenas o alfabeto, o quadro de sílabas ${ }^{9}$ e textos laicos. Se, nos silabários ou nos abecedários brasileiros localizados, os conteúdos religiosos ou textos sabidos de cor não

\footnotetext{
9 Estudos realizados sobre a administração de documentos
} recopiados por curas e indígenas bolivianos no período pós-jesuítico, no arquivo do Colégio S. Calixto, em La Paz, vão mencionar, entre os diversos materiais, uma cartilla e doctrina cristiana que conjuga alfabeto, silabário e doutrina religiosa, e outros materiais que só apresentam a doutrina (Saito; Beltran, 2005). 
estão presentes, encontramos um deslocamento fundamental na forma de ensinar/aprender, porque não se permite redescobrir, na alfabetização, um texto conhecido através da transmissão oral em contexto de práticas religiosas, e resta tentar decifrar fragmentos ou textos completamente novos. Se o texto a ser lido não é antes conhecido, fica mais difícil usar um conhecimento prévio para descobrir as relações entre o oral e o que está escrito.

Em contrapartida, sabe-se que existe um processo mais amplo de disseminação da cultura escrita para além da escola e que alguns materiais podem ter sido transferidos de um espaço de transmissão para outro. Em Minas Gerais, encontramos mapas escolares com informações sobre o desempenho de alguns alunos, descrevendo que alguns deles vinham com conhecimento mais avançado e estariam infrequentes, supostamente por já saberem o que seria ensinado. Talvez fosse porque as cartas de $A B C$ ou silabários circulavam em espaços domésticos e possibilitavam uma transmissão mais simples. Se esses materiais tinham estrutura previsível e conteúdo permanente e se os procedimentos de uso são tipificados, podem ter sido favorecidos tanto uma transmissão da leitura fora da escola como o autodidatismo.

De outra maneira, até quase o final do século XIX, parece que só há um caminho para aprender a ler: a soletração, e não há um método complicado que precise ser dominado. Aprendem-se os nomes das letras do alfabeto, reconhece-se cada letra fora da ordem, soletra-se seu nome, decoram-se alguns quadros de sílabas e depois se tenta redescobri-las em palavras ou textos. Nas palavras e nos textos, há uma separação por hífens ou espaços que vão guiando a oralidade. Podemos supor que uma pessoa que tenha aprendido por esse procedimento na escola pode transmitir essa "tecnologia de uso" para outros, em espaços escolares e não escolares. Repetir sempre os mesmos procedimentos pode dar uma ideia de estabilidade e simplicidade, incentivando leitores a utilizar, de forma mais autônoma, esse tipo de impresso. Talvez seja por isso que esse material se prolonga para além do tempo e do espaço da escola.
Precisamos continuar a procurar abecedários e/ou silabários para constatar algumas diferenças e similitudes em relação a outros contextos, como o francês, por exemplo. Mas, se esses materiais circularam e foram popularizados, constatamos a sua ausência em acervos. Além disso, cartas de $A B C$ e silabários por vezes parecem designar o mesmo material e em outras ocasiões parecem ser outro suporte. Embora vários livros produzidos no final do século XIX procurem romper com essa tradição, os prefácios dos livros denominados "Primeiros livros de leitura" - um produzido por Abílio César Borges (1867) e outro por Felisberto de Carvalho (1926) ${ }^{10}$ - mencionam os silabários ora como um tipo de ensino a ser superado, em função da ausência de sentido (Abílio); ora como material a ser criticado; ora como material a ser utilizado antes de os iniciantes fazerem uso dos primeiros livros de leitura (Felisberto de Carvalho). Sendo assim, podemos dizer que a palavra "silabário" pode ter mais de um sentido, designando: (i) um tipo de livro; (ii) uma tabela ou um conjunto de tabelas com séries silábicas variadas, apresentadas no interior das páginas de um livro; (iii) um método para alfabetizar.

Como vimos na descrição dos materiais do início do século XIX, esse termo ainda pode designar folhas soltas - possivelmente cartonadas - chamadas "cartas de sílabas". Além disso, podemos denominar como silabário qualquer livro para ensinar a ler, o que indica que, pela força da tradição, a palavra aparece num título/capa de livro. ${ }^{11}$

${ }^{10}$ Diversas pesquisas indicam que a primeira edição foi publicada em 1892 (Mortatti, 2000).

${ }^{11}$ Analisando fotos de diversos silabários, utilizados no Chile, que ilustram abundantemente um exemplar do jornal Patrimônio Cultural (Dirección de Bibliotecas, Archivos y Museos. 52, año XIV, diciembre 2009), encontramos páginas de diferentes silabários em formato de livros, um sem data (p. 17) e outros editados em 1886 (p. 20), 1947 (p. 2) e 1986 (p. 16). Na página 2, é apresentada a foto de um estande de silabários antigos e modernos reproduzida de um arquivo fotográfico do Museo de la Educación 


\section{Uma descrição de silabários e cartas de $\mathrm{ABC}$ localizados em acervos brasileiros}

A seguir, serão analisados alguns livros brasileiros em cujo título aparece a palavra silabário ou cartas de ABC.

Um silabário localizado em dois acervos brasileiros (LIVRES/USP e Centro de Referência do Professor), cuja edição é de 1879 , merece uma análise especial. É constituído de um exemplar de 120 páginas ilustradas em bico de pena, com excelente projeto gráfico. O Syllabario Portuguez ou novo método para aprender a ler em breve tempo a língua portuguesa e o sistema métrico ilustrado com numerosas estampas, de J. R. Galvão, apresenta-se como uma tradução e assinala em sua contracapa que "é adoptado em muitas escolas d'este império". Trata-se de uma obra traduzida e pode ter-se servido de modelos produzidos para outro público, para outros contextos de circulação e com outras tecnologias de transmissão. Publicado e composto no Rio de Janeiro, esse livro apresenta como locais de compra todas as livrarias da Bahia, de São Paulo e de Pernambuco. Há nele uma advertência de que antes deve ser usado um Alphabeto Portuguez, também composto pelo mesmo autor. As expressões usadas na breve apresentação "tem sido adotado este livro para uso das escolas públicas" e "Ultimamente foi adoptado em diversas províncias" deixam dúvida sobre seu público destinatário: crianças de posse ou crianças de escolas públicas? Também não é possível esconder algumas características que fazem dele um livro mais luxuoso: pelas estampas, pela qualidade do papel e pelo número de páginas. Seria ele usado para o ensino doméstico e de caráter individual? Apenas para escolas privadas? Como ele chega a ser adotado nas escolas públicas?

Sua estrutura e seu formato são uma mescla das descrições do alfabeto ilustrado e dos abecedários feitas

Gabriela Mistral (p. 3). Tendo em vista como títulos, podemos reforçar mais ainda a hipótese de que, em alguns casos, a expressão silabário pode não se referir apenas a um método/livro utilizado no século XIX, mas ser uma designação utilizada para qualquer livro para ensinar a ler. por Anne-Marie Chartier (2004, 2007). Apresentam-se, em suas primeiras páginas, um alfabeto e depois um alfabeto ilustrado, composto, com exceção de dois temas, de descrição de animais. A primeira leitura é antecedida de três listas de palavras que vão aparecer no texto para que seja feito o exercício de soletrar, e depois vem o primeiro texto, com palavras separadas por hífens e numeração nos parágrafos. O mecanismo parece ser simples: soletra-se e depois se reconhece. $\mathrm{Na}$ segunda leitura, as palavras da lista prévia são separadas por hífen, outra pista para saber até onde se soletra.

O que caracteriza esse material como sendo da família dos abecedários e dos alfabetos ilustrados é também outra parte de seu conteúdo: quase todos os textos de leitura são feitos a partir de temas religiosos, como a história da criação do mundo, passagens da Bíblia, pecados, virtudes e vícios e alguns comportamentos, mas não são as preces o que é dado a ler, mas narrativas. Ao final, também são apresentados alguns conteúdos de tipo enciclopédico, como conhecimentos de mapas, e de matemática.

Talvez esse material suponha uma intervenção individual de alguém que vai ler para a criança enquanto aponta o texto, ou até que ela decore para fazer um uso mais intensivo dos textos, uma vez que não são preces, mas narrativas muito detalhadas.

Com a denominação silabário, encontramos na Biblioteca Nacional (BN) o Syllabario ou Primeiro Livro de Leitura, de M. Ribeiro Almeida, edição de 1875, que é citado por Felisberto de Carvalho como um bom silabário. Esse parece fugir ao modelo que se caracteriza em apresentar, em primeiro lugar, algumas páginas com alfabetos e tabelas de sílabas, uma vez que destaca palavras desde a primeira lição, e seu prefácio aos professores demonstra ser esse um livro que passa por ordenamentos escolares mais sofisticados, mais próximos dos modelos de livros que virão depois.

Repertoriamos também, na BN, o Silabário Prima $A B C$, sem autoria, de $1954,{ }^{12}$ mas tendo no título o

${ }^{12}$ A descrição do exemplar de 1954 pode ajudar a compreender o formato e suas transformações; essa data atesta sua permanên- 
nome da editora: Prima Editora de Pernambuco. Esse é um exemplar típico das edições populares, em 16 páginas, com capa e miolo que não se distinguem em termos do tipo de papel utilizado. Não há nele nenhum discurso pedagógico, nenhuma observação quanto ao público. A estrutura desse silabário parece ser aquela das primeiras partes dos abecedários de Troyes: da página 1 a 3, vários alfabetos e números, silabários de uma página (à moda de um tableau?) com todas as sílabas diretas envolvendo todas as letras do alfabeto, alternado com texto, seguido de outros silabários com ditongos, com sílabas em posições inversas. Após cada quadro de sílabas, também são apresentadas palavras e frases separadas por hífens. Seria esse um livro de circulação popular? Sua publicação pode ter ocorrido bem antes, mas a edição conservada é contemporânea àquela que vai trazer, desde o final do século XIX, modelos de livros para alfabetizar ordenados por um tipo de lógica escolar que trabalha com seções, graduação de conteúdos, exercícios de escrita, prefácios com instruções metodológicas, entre outras características.

Sob a denominação Cartas do ABC para principiantes, localizamos na $\mathrm{BN}$ um material próximo ao silabário, sem data nem editora, publicado na Bahia e com apenas 16 páginas. Nele é apresentada a seguinte estrutura: apresentação do alfabeto completo em imprensa maiúscula e depois separando vogal de consoante. Em seguida, o alfabeto minúsculo, depois o alfabeto manuscrito maiúsculo e minúsculo. Depois são apresentados exercícios com vogais e consoantes (sílabas referentes a cada consoante) e, ao final, um exercício de leitura e o hino nacional. A ausência de data e dados editoriais parece ser comum em alguns desses materiais que aparentemente eram destinados a usos populares. Sabe-se que o gênero cartas de ABC circula contemporaneamente, sobretudo no Nordeste, e que esses livros fazem parte de um circuito extraes-

cia de uso. Os dados sobre a região em que foi produzido indicam o lugar/região onde esse material pode ter circulado. Dessa forma, decidiu-se por incorporá-lo no corpus. colar de distribuição e uso: é possível adquiri-los atualmente em feiras e gráficas populares.

Outro material localizado no mesmo acervo denomina-se $A B C$ da infância - introdução ao livro de infância. Primeira Colleção de Cartas para aprender a Ler, ${ }^{13}$ exemplar de 32 páginas, sem autor, publicado pela Livraria Francisco Alves. Localizamos na BN três edições: $56^{\mathrm{a}}$ e $57^{\mathrm{a}}$, ambas de 1908 ; e a $104^{\mathrm{a}}$, publicada em 1954. Se o exemplar de 1908 está na 56a edição, podemos supor que ele tenha circulado no século XIX. O seu título traz uma informação fundamental: "primeira coleção de cartas”. Essa é uma pista interessante, pois parece anunciar que aquelas cartas que vinham soltas estão agora compiladas em formato de livro e que foi uma publicação pioneira.

Essa obra parece dialogar com as práticas de educação doméstica, pois o "diretório" de uma página, com instruções de uso, faz uma dedicatória explícita: "Das mães que se dedicam ao ensino de seus filhos (a mais nobre e gloriosa missão de mulher)". São dadas instruções em três tópicos: instruções sobre como fazer a criança articular corretamente letras, sílabas e palavras; regras de leitura em voz alta com sua pontuação e lições de coisas. A instrução explicita a necessidade de que "logo que o menino aprenda a soletrar, que se explique o valor de cada palavra que ele vai aprendendo, em seguida, o ensino de coisas animadas e inanimadas, que a boa mãe poderá ler nas Lições de Cousas de A. Zaluar".

Todas as páginas destacam um título, e podemos distinguir cinco partes: alfabeto redondo; nove cartas de sílabas; três cartas de nomes; sinais de pontuação e carta para soletrar com histórias separadas por hífen. Comparando os dois silabários com 16 páginas descritas, parece haver um discurso mais explícito e "pedagogizado" sobre formas de uso, um pequeno aumento de quadros de sílabas e de textos e um ace-

${ }^{13}$ Nas páginas finais da edição há uma sugestão: “O livro da Infância, de Zaluar, é o livro mais próprio para continuação dos exercícios de leitura em seguida a este syllabário”. Se um livro denominado "Cartas de ABC" é também referido como silabário, podemos dizer que não há muita distinção entre os tipos de livros. 
no do nome do livro a ser lido depois, ou melhor, da prática que o continua.

Podemos indagar: tendo em vista um discurso pedagógico sobre seu uso e tendências relacionadas ao método intuitivo, até que ponto essa edição partilha características de livros didáticos mais consagrados e ligados aos modelos escolares publicados por essa editora, uma das mais importantes no mercado editorial de livros para a escola? Até que ponto visa a um público doméstico que sabe seguir as instruções pedagógicas? Ou seria também dirigido a um público popular, nesse mesmo período e no decorrer dos outros anos? $\mathrm{O}$ fato é que esse livro ainda continua a ser publicado em 1954, num período em que há diferentes modelos de livros editados na mesma casa, já referidos a métodos sintéticos e analíticos, e de autores renomados.

Por fim, poderíamos indagar: onde esse material mais popular, denominado Cartas do ABC e Silabário, circula quando não na escola? Para qual tipo de prática? Não podemos comparar as datas, e pode ser uma coincidência o fato de dois deles terem sido produzidos na mesma região, mas podemos estabelecer uma hipótese da permanência de uso desses materiais em algumas regiões para além do período investigado. Cartas de $\mathrm{ABC}$ são materiais que circulam até hoje, mas em circuitos paralelos ao da escola.

De maneira geral, constata-se que os modelos de livros que começam a surgir no final do século XIX vão negar esses silabários. A pesquisa dos novos modelos de livros que os sucederam permitirá verificar a produção de outros dispositivos para colocar o ensino da escrita nas páginas dos livros e também para verificar os efeitos da escola, que vai se tornando, progressivamente, a guardiã das formas de transmissão da cultura escrita.

\section{Considerações finais}

Este estudo visou recuperar certo "percurso" no decorrer do século XIX, tanto do uso como dos formatos de materiais para ensinar a ler. Verificamos que vários deles também foram utilizados em outros países, com fins diversos ou semelhantes, daí a necessidade de se pensar nas circulações envolvidas nos materiais e nos usos da cultura escrita. Com essa discussão, almejamos acrescentar mais elementos que indicam como os materiais impressos apresentavam-se em determinado momento histórico, auxiliando futuras pesquisas que visem produzir uma "sociologia dos textos" e uma história de seu uso escolar.

O estudo sobre a morfologia dos livros didáticos pode valer-se de estratégias metodológicas que auxiliem uma melhor percepção das heranças, das permanências e das inovações nos impressos, nos métodos de ensinar, nos contextos escolares e educacionais. Os livros brasileiros para ensinar a ler de Abílio César Borges, de Felisberto de Carvalho e de Hilário Ribeiro, produzidos no final do século XIX, dialogam com representações e formatos construídos antes. A investigação dos materiais que antecederam esses livros é valiosa para pensar funções, métodos, conteúdos, usos e manuseios de impressos no espaço escolar e mesmo para refletir sobre a sua circulação em mais de uma esfera cultural, dentre elas, a doméstica, a escolar ou a religiosa.

O estudo de seus formatos e seus usos pode contribuir para reflexões sobre como os impressos/livros dialogam com outros públicos no espaço extraescolar ou como são reformulados ou criados pelos próprios agentes que passam a transmitir, na escola, os princípios da escrita.

A análise de fontes primárias em que aparecem citados os materiais atesta sua possível presença na escola, mas podemos dizer que algumas explicações para seu uso nem sempre vêm atreladas ao que conhecemos hoje como métodos de alfabetização. Além disso, na constituição do espaço/práticas escolares, a escrita na escola não só é objeto de ensino, mas também cumpre diferentes funções, inclusive a de organizar o trabalho escolar.

A recuperação de uma genealogia dos materiais impressos no século XIX, período em que a escola está inventando modos próprios ou dialogando com outras formas de transmissão da escrita, faz-nos dialogar com a história do livro, com a história da cultura escrita e, mais especialmente, com aqueles que investigam a construção histórica da escola e da "alfabetização". 


\section{Referências bibliográficas}

BENITO, Agustin Escolano (Org.). História ilustrada del libro escolar en España. Del Antiguo Régimen a la Segunda República. Madrid: Fundación Germán Sánchez Ruipérez, 1997.

CABRINI, Conceição Aparecida. Memória do livro didático. Os livros de leitura de Felisberto Pereira de Carvalho. 1994. Dissertação (Mestrado em Editoração e Jornalismo). ECA-USP. Universidade de São Paulo, São Paulo, 1994.

CHARTIER, Anne-Marie. Des abécédaires aux méthodes de lecture: gènese du manuel moderne avant les lois Ferry. Mimeo. 2004. 37p. . Práticas de leitura e escrita. História e atualidade. Belo Horizonte: Autêntica, 2007.

CHARTIER, Roger. A história cultural: entre práticas e representações. Rio de Janeiro: Difel, 1990. p. 121-139.

. A ordem dos livros: leitores, autores e bibliotecas na Europa entre os séculos XIV e XVIII. Brasília: Universidade de Brasília, 1994.

. (Org.). Práticas da leitura. São Paulo: Estação Liberdade, 1996.

. (Coord.). As utilizações do objeto impresso. Portugal: Difel, 1998a.

. A aventura do livro do leitor ao navegador. São Paulo: Unesp, 1998b.

A ordem dos livros: leitores, autores e bibliotecas na Europa entre os séculos XIV e XVIII. Tradução de Mary del Priore. Brasília: Universidade de Brasília, 2004.

CHOPPIN, Alain. O historiador e o livro escolar. Revista História da Educação, Pelotas, UFPel, n. 11, p. 5-24, 2002.

FARIA FILHO, Luciano Mendes de; CHAMON, Carla; ROSA, Walquíria Miranda. (Orgs.). Educação elementar. Minas Gerais na primeira metade do século XIX. Belo Horizonte: UFMG, 2006.

FERRARO, Alceu Ravanello. História inacabada do analfabetismo no Brasil. São Paulo: Cortez, 2009.

FRADE, Isabel Cristina Alves da Silva Frade; MACIEL, Francisca Izabel (Orgs.). História da alfabetização: produção, difusão e circulação de livros (MG/RS/MT - séc. XIX e XX). Belo Horizonte: UFMG/FAE/FAPEMIG/CNPq, 2006.

HALLEWELL, Laurence. O livro no Brasil (sua história). São Paulo: Edusp, 1985.

HÉBRARD, Jean. Os livros escolares da Bibliothèque Bleue: arcaísmo ou modernidade? Revista Brasileira de História da Educação, n. 4, p. 10-45, jul./dez. 2002
INÁCIO, Marcilaine. O processo de escolarização e o ensino das primeiras letras em Minas Gerais (1825-1852). Dissertação (Mestrado em Educação) Faculdade de Educação. Universidade Federal de Minas Gerais. 2003.

INÁCIO, Marcilaine; FARIA FILHO, Luciano; ROSA Walquíria; SALES, Zeli Efigênia.(Orgs.). Escola, politica e cultura. Belo Horizonte: Argumentum/CNPq, 2006.

LAJOLO, Marisa; ZILBERMAN, Regina. A formação da leitura no Brasil. São Paulo: Ática, 1996.

LE MEN, Ségolène. Les abécédaires français illustrés du XIXe siècle. Paris: Promodis, 1984.

MACIEL, Francisca I. P. Ler, escrever e contar... a história da alfabetização em Minas Gerais. Belo Horizonte: SEE/MG, 2003. Catálogo de exposição.

MCKENZIE, Donald. La bibliographie et la sociologie des textes. Paris: Éditions du Cercle de la Librarie, 1991.

MORTATTI, Maria do Rosário. Os sentidos da alfabetização. São Paulo: UNESP, 2000.

SAITO, Akira; BELTRAN, Clara. Usos del documento y câmbios sociales en la historia de Bolivia. Japan: National Museum of Etnology, 2005.

\section{Livros brasileiros consultados}

ABC da infância - introdução ao livro de infância. Primeira Colleção de Cartas para Aprender a Ler. Rio de Janeiro, São Paulo, Belo Horizonte: Livraria Francisco Alves. Exemplares da 56.ed. e da 57.ed. (ambas de 1908) e da 104.ed. (1954).

Cartas do ABC para principiantes. Bahia: [s.n.], [s.d.].

Primeiro livro de leitura para uso da infância brasileira, composto pelo Dr. Abilio César Borges - Director do ... bahiano, et. Paris: Livraria de V.va. J. Aillaud. Guilllard E. C.47, Rua Saint-Andredes-Arts., 1867

Primeiro livro de leitura. Felisberto de Carvalho. Desenhado e refundido por Epaminondas de Carvalho. Rio de Janeiro: Livraria Francisco Alves, 1926

Syllabario Portuguez ou novo método para aprender a ler em breve tempo a língua portuguesa e o sistema métrico ilustrado com numerosas estampas. Traduzido e composto por J. R. Galvão do Rio de Janeiro. Venda em todas as livrarias do Rio de Janeiro, Bahia, Pernambuco e S. Paulo, 1879.

Syllabario ou Primeiro Livro de Leitura, de M. Ribeiro Almeida. Rio de Janeiro: Typografia Perseverança, 1875.

Silabário Prima AB.. Pernambuco: Prima Editora, 1954. 


\section{Livros franceses consultados}

DESSIRIER, J. B. Méthode facile pour apprendre a lire. Besançon: Chez Billote, Libraire-Pepetier, 1853. . Notice pédagogique sur la méthode de lecture en deux tableux et trois livrets de M.P. Néel. Paris: Librairie Classique Armand Colin et Cie., 1889.

ISABEL CRISTINAALVES DA SILVA FRADE, doutorado em educação pela Universidade Federal de Minas Gerais (UFMG), com pós-doutorado realizado na Faculdade de Educação da Universidade de São Paulo (USP) e no Institut National de Recherche Pédagogique (INRP/França), é professora do Programa de PósGraduação em Educação da UFMG, pesquisadora do Centro de Alfabetização, Leitura e Escrita (CEALE) da UFMG e bolsista de produtividade do CNPq. Últimas publicações: organizou com MACIEL, Francisca Izabel. História da alfabetização: produção, difusão e circulação de livros (MG/RS/MT - Séc. XIX e XX).
(Belo Horizonte: UFMG/FAE/FAPEMIG/CNPq, 2006); e com SCHWARTZ, Cleonara; PERES, Eliane. Estudos de história da alfabetização e da leitura na escola (Vitória: EDUFES, 2010); Suportes, instrumentos e textos de alunos e professores em Minas Gerais: indicações sobre usos da cultura escrita nas escolas no final do século XIX e início do século XX (Revista História da Educação, v. 13. n. 29, p. 29-55, set./dez. 2009). Pesquisas em andamento: "Cartilhas: ideários, práticas pedagógicas e editoriais: construção de repertórios analíticos e de conhecimento sobre a história da alfabetização, do livro, da leitura e das práticas editoriais - MG/RS/MT/ES/AM/UFF" e "Uma história da alfabetização em Minas Gerais: conteúdos, produção e características de materiais e objetos escolares e modos de escolarização da cultura escrita - Séculos XIX e XX”.

E-mail: icrisfrade@gmail.com

Recebido em março de 2009

Aprovado em abril de 2010 
Isabel Cristina Alves da Silva Frade

Uma genealogia dos impressos para o ensino da escrita no Brasil no século XIX

O objetivo deste artigo é caracterizar e compreender diferentes modelos e formatos de livros escolares ou de outros impressos para ensinar os princípios da escrita, utilizados na Província de Minas Gerais e no Brasil a partir do início do século XIX. Anterior a uma produção escolar mais autoral de livros para ensinar a ler, encontramos menções sobre o uso de abecedários, cartas do ABC e silabários. Na ausência de materiais conservados, buscaram-se indícios de como eles se apresentavam e eram utilizados em fontes primárias (correspondências, relatórios, mapas de desempenho) produzidas na Província de Minas Gerais, desde 1823. Com essas fontes, problematizamos o uso de tabelas, tábuas e cartas. Outro conjunto de fontes analisado é constituído por quatro livros brasileiros e um livro traduzido para o português, cujos títulos continham as denominações silabário, abecedário e cartas de ABC. A investigação baseia-se não só nos campos da história da leitura e do livro (Roger Chartier), que abordam as formas dos textos, dos impressos e de seus usos, mas também nos estudos da história da alfabetização e da educação, no mesmo período. Para uma análise comparativa, fontes secundárias francesas ajudam a compreender a forma e os usos de tabelas, abecedários e silabários.

Palavras-chave: impressos, tábuas, tabelas, cartas de ABC, silabários, abecedários, história da alfabetização, cultura escrita, escolarização da escrita.

\section{A genealogy of printed material for teaching writing in Brazil in the nineteenth century \\ The aim of this article is to characterize and understand the different models and formats of textbooks or other printed material for teaching the basics}

of writing, used in the Province of Minas Gerais and in Brazil, from the early nineteenth century. Before the production of more authorial books to teach reading at school, we find mention of the use of literacy primers, $A B C$ letters and first reading books. In the absence of well preserved materials, we searched for evidence of how they were presented and used, in primary sources (correspondence, reports, performance charts) produced in the Province of Minas Gerais since 1823. With these sources the use of tables, boards and letters was problematised. Another set of sources examined is composed of four Brazilian textbooks and a book translated into Portuguese, whose titles contained such denominations as first reading book, literacy primers and ABC letters. The research is based not only on studies related to the history of books and reading (Roger Chartier), which deal with the types of text, printed matter and their uses but also to studies on the history of literacy education in the same period. For a comparative analysis, French secondary sources help to understand the form and uses of tables, literacy primers and first reading books.

Key words: printed material, boards, tables, ABC letters, first reading books, literacy primers, history of literacy, written culture, school taught writing

Una genealogía de los impresos para la enseñanza de la escrita en Brasil en el siglo XIX

El objetivo de este artículo es caracterizar y comprender diferentes modelos y formas de libros escolares o de otros impresos para enseñar los principios de la escritura, utilizados en la Provincia de Minas Gerais y en Brasil a partir del inicio del siglo XIX. Anterior a una producción escolar más autoral de libros para enseñar a leer, encontramos menciones sobre el uso de abecedarios, cartas de $A B C$ y silabarios. En la falta de materiales conservados, se buscaron indicios de cómo ellos se presentaban $y$ eran utilizados, en fuentes primarias (correspondencias, velatorios, mapas de desempeño) producidas en la Provincia de Minas Gerais, desde 1823. Con estas fuentes, se problematiza el uso de tablas y cartas. Otro conjunto de fuentes analizado es constituido por cuatro libros brasileños y un libro traducido para el portugués, cuyos titulos contenian las denominaciones silabario, abecedario y cartas de $A B C$. La investigación se fundamenta no sólo en los campos de la historia de la lectura y del libro (Roger Chartier), que abordan las formas de los textos, de los impresos y de sus usos, como también en los estudios de la historia de la alfabetización y de la educación, en el mismo periodo. Para un análisis comparativo, fuentes secundarias francesas ayudan a comprender la forma $y$ los usos de tablas, abecedarios y silabarios.

Palabras clave: impresos, tablas, cartas de ABC, silabarios, abecedarios, historia de la alfabetización, cultura escrita, escolarización de la escritura.

Carlota Boto

\section{A dimensão iluminista da reforma pombalina dos estudos: das} primeiras letras à universidade O presente artigo tem por propósito discutir o tema da educação à luz da intersecção entre os ideais políticos e pedagógicos de três pensadores iluministas portugueses - Dom Luís da Cunha, António Nunes Ribeiro Sanches e Luiz António Verney - e a reforma dos estudos empreendida pelo Marquês de Pombal. A ação de Pombal como ministro do reino português foi, em certa medida, embasada por reflexões teóricas acerca de Portugal e da crise do império português. Essas reflexões, entre outros aspectos, destacavam ser uma necessidade histórica para o desenvolvimento do país o Estado português tomar para si o controle das questões do ensino em todos os seus níveis. Ao expulsar os jesuítas, ao 